\title{
EM BEJA COM OS OLHOS NO MUNDO - O PAPEL DOS MEIOS DE INFORMAÇÃO NO EPISCOPAdo de FRei MANUEl do CENÁCulo ${ }^{1}$
}

\author{
Francisco António Lourenço Vaz \\ (Professor do Departamento de História - Universidade de Évora)
}

\section{RESUMO}

D. Manuel do Cenáculo Villas Boas entrou na diocese em Março de 1777, com um programa reformista bem delineado e que tinha nos meios de informação do seu tempo o suporte indispensável para sua implementação. Efectivamente, das suas cartas ressalta a vontade de transformar Beja numa espécie de pólo cultural, como que a pretender colocar a cidade no mapa, não apenas nacional mas também europeu. Com a presença efectiva do prelado, Beja ganhou um dinamismo cultural surpreendente, com as diversas iniciativas e projectos, que levou a cabo. São prova dessa nova dinâmica os muitos visitantes nacionais e estrangeiros que ai passam durante o seu episcopado, os estudos que cria para os seus párocos, as conferências eclesiásticas, a criação de uma bibliotecamuseu que abriu ao público, os projectos arqueológicos que desenvolveu no terreno, nomeadamente, em Tróia e Sines.

Temos defendido em anteriores trabalhos que Cenáculo era um homem de projectos, que com a sua acção em prol da ciência e da cultura se transformou num autêntico Príncipe das Letras do Alentejo, um mecenas para todos os que se aventuravam nos caminhos das Belas Artes e das Belas Letras e recorriam ao seu patrocínio. Com esta comunicação fazemos um balanço do dinamismo cultural e científico que a cidade alentejana passou a ter durante o seu episcopado e aferimos a importância que a correspondência, os livros e outros meios de informação tiveram para pôr no terreno os projectos do bispo.

\section{Palavras Chave - Instrução, Meios de Informação, Livros, Biblioteca.}

\footnotetext{
1 - Texto Publicado em: O Alentejo entre o Antigo Regime e a Regeneração. Mudanças e Permanências/ Colóquio, Ed. FONSECA, Teresa e FONSECA, Jorge, Lisboa, Edições Colibri- CIDEHUS-EU - Centro Interdisciplinar de História, Culturas e Sociedades da Universidade de Évora, 2011, ISBN: 978-989-689090-2, p. 209-230.
} 


\begin{abstract}
D. Manuel do Cenáculo Villas Boas joined the diocese in March 1777 with a reformist program that it had in the media of his time the support necessary for its implementation. Indeed, from his letters underscores the desire to make Beja a kind of cultural centre, as if he wants to put the city on the map, not only national but also European. With the presence of the prelate, Beja won a surprising cultural dynamism, with the various initiatives and projects he has undertaken. They are proof of this new dynamic the many national and foreign visitors passing through town during his episcopate, studies establishing for their pastors, church conferences, the creation of a library-museum that opened to the public, archaeological projects in developing ground, in particular, Sines and Troia.

We have argued in previous work that Cenáculo was a man of projects, and that with his action in favour of science and culture became a real Prince of Letters of Alentejo, a patron of all who ventured on the roads of Fine Arts and Fine Letters and resorted to their sponsorship. With this paper we seek to take stock of scientific and cultural dynamism that the Alentejo town now has during his episcopate and to assess the importance of correspondence, books and other media had to put the projects on the ground of the Bishop.
\end{abstract}

Keywords - Education, Media Information, Books, Library. 


\section{Do desencanto ao poder das notícias}

Não foi gloriosa a saída de D. Manuel do Cenáculo de Lisboa, onde durante anos fez parte do círculo do poder político. De facto, o que expressou nas páginas do seu Diário, em Março de 1777, foi um grande desencanto e desilusão. Desencantado com a atitude da elite lisboeta que uma vez caído o poderoso ministro depressa passou a apontar o dedo aos que o rodeavam e a transformá-los em alvo da chacota pública e do mexerico das ruas da capital ${ }^{2}$. Desiludido com a família real, incluindo o Príncipe D. José, que educara e com quem convivera. Desiludido até com os frades Terceiros, que vendo a cor política mudar também procuravam a indispensável adaptação para continuar a usufruir das benesses do poder, ou seja, dos cargos e proventos que fornecia.

Mas o bispo não era homem para se deixar abater por desânimos e pelos mexericos ou intrigas. O seu estoicismo iria posteriormente ter que se aplicar em situações bem mais adversas. Agora que contava 57 anos era um homem com ideias bem precisas e com vontade de as fazer germinar. De facto, o próprio Cenáculo, durante a viagem para a diocese, delineou no Diário as linhas da sua actuação.

Pregar: exortar: ensinar por todos os meios, e caminhos: dar esmolas, e empregar na minha Esposa quanto for meu de espírito, diligência, e possibilidade material e espiritual: educar a mocidade: dar bom exemplo, e propor-me aos Bispos que devo ter diante dos olhos: buscar pela humildade; e humilhações a minha expiação, que não falta do quê: estabelecer sãs doutrinas; e fazer o Clero aceitável em Fé, e digno das necessidades dos Povos ${ }^{3}$.

Dito na primeira pessoa, este programa tem em si o essencial daquilo que vai ser a sua actuação como Bispo. Podemos mesmo dizer que ele se resume na vontade de levar a instrução a todos os diocesanos. Se para o povo simples a instrução podia ser sinónimo de catecismo, para os párocos e restante clero, a instrução era muito mais abrangente, ou se preferirmos especializada, dados os objectivos enunciados de o tornar "aceitável na fé, e digno das necessidades dos povos". Num e noutro caso, são precisos meios de

\footnotetext{
2 - Entre os vários panfletos que então saíram na capital contra o Marquês de Pombal um deles era expressamente contra Frei Manuel do Cenáculo, apelidando-o de “Um Ninguém o debarrar destilado/ chegou a ser censor e Presidente». BN Ms. 1057 e Jaques MARCADÉ, Dom Frei Manuel do Cenáculo Vilas Boas. Éveque de Beja, Archevêque d'Evora (1770-1814), Paris, 1978, pp. 86-87. Nesta e nas restantes citações actualizámos a ortografia.

3 - Frei Manuel do CENÁCULO, Diario, cit. Francisco VAZ, D. Manuel do Cenáculo: Instruções

Pastorais, Projectos de Bibliotecas e Diário, Porto, Porto Editora, 2009, p. 140.
} 
informação, e entre estes avultam os livros que eram na época o principal suporte para adquirir o conhecimento.

Temos analisado em anteriores trabalhos, o papel dos livros e bibliotecas na acção reformista do Bispo de Beja ${ }^{4}$. Mas além dos livros, um bispo que pretende semear as suas ideias, precisa também de estar bem informado sobre o que vai acontecendo. Precisa de estar a par das notícias de Lisboa, mas também do que se passa na Europa e no Mundo.

Num estudo recente Robert Darnton defendeu que a sociedade parisiense, da segunda metade de setecentos, pode ser considerada um bom exemplo de uma sociedade de informação, porque nela as notícias circulavam, tal como hoje, recorrendo a diversos meios. É claro, que esses meios eram, em muitos casos, diferentes dos actuais e utilizavam muito mais o discurso oral e o manuscrito ${ }^{5}$. Chamar a esta sociedade uma sociedade de informação prematura pode ser considerada por muitos, que não estão atentos as questões da História da Informação, como um anacronismo, habituados como estamos no presente a considerar que só agora entramos na era da informação. Mas, na verdade, todas as sociedades são sociedades de informação, o que mudam são os meios e o tempo com que essa informação circula.

Convêm também reflectir sobre conceito de notícia. Em Portugal, o termo na sua acepção moderna, foi usado por Severim de Faria na sua principal obra: Notícias e Portugal, embora tenha sido com as relações que o autor deixou o nome ligado às origens da imprensa periódica em Portugal. Para nós é significativo que Severim de Faria associe o termo Notícias à sua principal obra e o utilize em diversas passagens, principalmente no singular ${ }^{6}$. Primeiro porque o termo não era naturalmente muito vulgar em 1655, depois porque o termo notícia em Severim de Faria parece ser sinónimo de informação, de conhecimento ou até de história ${ }^{7}$. Por outro lado, sabemos

\footnotetext{
4 - Francisco VAZ, coord., Os Livros e as Bibliotecas no Espólio de D. Frei Manuel Do Cenáculo, Lisboa, 2009.

5 - Robert DARTON, An Early Information Society, 2000, diponível em: http://www.indiana.edu/ ahr/darnton/texts/p03.html , Consultado em 24-9-2008.

6 - Inventariámos 30 referências quase todas no singular.

7 - Como sinónimo de informação, anote-se nas seguintes passagens: «.. notícia tão desejada até agora, e tão oculta a quase todos os que da Nobreza trataram, como se vê de seus escritos». Manuel Severim de FARIA (1655), Notícias de Portugal. Introdução e notas de Francisco VAZ, Lisboa, Colibri, 2003, p. $3 ;$ «... de entre eles saiu a artificiosa invenção do papel, de que hoje usamos, das quais cousas todos os antigos não tiveram notícia»; « ...de que Ptolomeu não podia ter perfeita notícia», Idem, p. 11; «Diogo Cão Capitão de valor indo por mandado del Rei D. João II descobrir a Costa de Etiópia, foi o primeiro, que deu notícia do rio Zaire». Idem, p. 101. Ou de história: « Os Castelos são antigas divisas das mesmas terras, como se pode ver largamente na notícia dos Impérios». Idem, p. 94;. «...Além das
} 
que o autor hesitou entre o singular e plural, como deixa documentado no prólogo dirigido ao leitor.

A obra de D. Manuel do Cenáculo e também o seu vastíssimo espólio mostram-nos que o conceito de noticia tinha a acepção que hoje lhe damos e mostra-nos igualmente que o público das Luzes estava como o de hoje sempre ávido de notícias. E não era certamente só nos jornais e gazetas oficiais que matava essa fome, por razões evidentes que Rober Darnton enumera no seu estudo ${ }^{8}$. Efectivamente, D. Manuel do Cenáculo, sobretudo a partir do momento que vai para Beja, é um bom exemplo de alguém ávido de noticias, porque foi certamente para as obter e estar ao corrente do que ia acontecendo que manteve durante todo o episcopado uma rede de correspondentes espalhada por todo o mundo. Mapear esta correspondência é um projecto que temos em curso há alguns anos. A dimensão desse espólio de cartas dirigidas a Cenáculo e também dos seus autógrafos, é impressionante. No quadro seguinte fazemos o ponto da situação, da nossa pesquisa a este fundo no âmbito do projecto concluido em Maio de 2009.

Quadro 1 - Correspondência de D. Frei Manuel do Cenáculo

\begin{tabular}{|l|l|l|l|}
\hline CARTAS & $\begin{array}{l}\text { Catalogadas por } \\
\text { GUZMÃO }\end{array}$ & $\begin{array}{l}\text { Catalogadas no } \\
\text { âmbito do projecto }\end{array}$ & Totais \\
\hline Enviadas por Cenáculo & - & 1013 & 1013 \\
\hline Dirigidas a Cenáculo & 4269 & 1134 & 5403 \\
\hline & & & \\
\hline TOTAL & $\mathbf{4 2 6 9}$ & $\mathbf{2 1 4 7}$ & $\mathbf{6 4 1 6}$ \\
\hline
\end{tabular}

Os originais desta correspondência encontram-se na Biblioteca Pública de Évora, Biblioteca da Academia das Ciências de Lisboa, Biblioteca Nacional, Biblioteca Pública de Braga e também na Biblioteca Nacional de Espanha ${ }^{9}$. Comecemos por fazer uma breve análise à correspondência que como a tabela nos mostra é constituída, pelo

quais também se apontarão algumas, que trazem outros Autores, para ficar a notícia desta matéria mais inteira». Idem, p. 138.

8 - Refere-se, nomeadamente, à censura e prevalência de um discurso oficial, bem como à dependência dos jornais e gazetas relativamente ao pode real.

9 - Na Biblioteca da Academia das Ciências as cartas encontram-se dispersas por 8 códices e um total de 1902 fólios; na Biblioteca Pública de Évora por 21 códices, um total de 3747 fólios. 
menos, por um acervo de 6.416 cartas, sendo1013 de Frei Manuel do Cenáculo e 5403 cartas de correspondentes ${ }^{10}$.

\section{A rede de correspondentes}

Para criar uma rede de correspondentes, tão vasta e numerosa, Frei Manuel dispunha de algumas condições favoráveis. A primeira foi a sua qualidade de frade da Ordem Terceira de S. Francisco, uma das numerosas famílias de frades Menores. A Ordem possibilitava, à semelhança de outras, o contacto com os conventos de outras nações, era portanto um excelente suporte para estabelecer contactos internacionais. De facto, introduzida em Portugal em 1521, pela Bula Inter cetera de Leão X, a Ordem estava unida às de Leão, Castela e Andaluzia e os assuntos eram tratados a uma escala ibérica. Do mesmo modo havia reuniões os capítulos gerais. Frei Manuel teve as suas duas idas ao estrangeiro nesta qualidade. De facto, foi como membro da delegação enviada a Roma pela Província Portuguesa dos Regulares da Ordem Terceira, para participar no capítulo geral da Ordem realizado em Roma em 1750, que Cenáculo fez a sua primeira viagem ao estrangeiro. Durante esta viagem percorreu a Espanha, começando em Badajoz seguindo para Madrid, e Barcelona; passou depois para França pelo Roussilon, Languedoc e Dauphiné e na Itália Milão, a Toscana e depois Roma. Na companhia de seu Mestre Frei Joaquim de S. José e de Frei Domingos da Encarnação, pode então visitar bibliotecas, museus e universidades, ficando assim a par do que se ia fazendo de mais actual e inovador nesse domínio. Esta viagem será por ele recordada como determinante no seu percurso e ideias ${ }^{11}$. A segunda viagem, feita já na qualidade de Provincial da Terceira Ordem, foi uma pequena estada em Valência, em 1768, para participar no Capítulo Geral.

Foi naturalmente aproveitando este carácter internacional dos Terceiros, e mesmo estas duas viagens, que Frei Manuel criou laços de amizade e conhecimentos que depois se traduziriam na correspondência que manteve com outros clérigos e

\footnotetext{
10 - É provável que se encontrem muitas outras cartas de Frei Manuel do Cenáculo em outras bibliotecas, para lá daquelas onde decorreu o trabalho de campo do projecto. Temos noticia que na Biblioteca Pública de Braga há correspondência por catalogar e o mesmo pode acontecer em bibliotecas nacionais e estrangeiras.

11 - A viagem está descrita em BPE, Cod. CX/1-10, Diário da Jornada a Roma, texto que segundo alguns é da autoria de Frei Manuel do Cenáculo e que para outros dificilmente se lhe pode atribuir. J. MARCADÉ, Dom Frei Manuel do Cenáculo Vilas Boas. Éveque de Beja, Archevêque d' Evora (17701814)..., p. 499.
} 
regulares. Estão naturalmente neste caso Frei João Molina, os irmãos Mohedanos, Frei Pedro e Frei Rafael Mohedano, Juan Buytrago, Gregório Mayans e Siscar ${ }^{12}$.

A Ordem Terceira possibilitava também as ligações e correspondência a nível nacional, com a sua vastíssima rede de conventos que cobriam o território nacional, incluindo os territórios ultramarinos. Só no território nacional a ordem tinha 4 casas no Norte: Mogadouro, Sesulfe (Nossa Senhora das Flores), Marialva, S. João da Pesqueira; e 6 casas no Sul: Lisboa, Coimbra, Viana do Alentejo, Monchique, Silves e Vimieiro ${ }^{13}$.

Foi à sombra da Ordem Terceira que Cenáculo fez os seus estudos, que os completou com uma autentica viagem instrutiva, e foi esta ligação aos terceiros que, mesmo depois de ser bispo de Beja, lhe possibilitou uma rede de correspondentes que cobria o território nacional e com importantes pontos a nível internacional. As ligações aos frades da Ordem estarão sempre presentes, ao longo do seu episcopado: muitos dos professores dos estudos que implementou em Beja são jovens frades franciscanos, como Frei Plácido Barroco. Muitos dos que alimentaram a sua bibliofilia são monges, como Frei Gregório Viegas, .... É também nos frades da Ordem Terceira que recruta os que o apoiam na criação de bibliotecas e museus, como Frei Lourenço do Valle a quem incumbe de organizar o museu bejense, ou a Frei Vicente Salgado que lhe dá importantes informações sobe as antiguidades e arqueologia. Enfim, o intercâmbio literário que Cenáculo manteve com os regulares demonstra um autêntico trabalho de equipa, em que desde os mais pequenos contributos, como as numerosas obras que lhe são dedicadas por muitos frades, até aos grandes contributos como organizar a biblioteca-museu, são orientados para o reformismo que o Bispo bejense quer desenvolver e que tem nos meios de informação do seu tempo a base.

Cenáculo fez um autêntico cursus honorum, na sua ordem e que contribuiu de forma decisiva para alcançar uma outra condição ou estatuto que favorecerá a criação de uma rede de correspondentes e informadores, a sua entrada para o circulo de poder. De facto, a simples cronologia dos cargos que foi ocupando nos mostra esta conexão.

- 1739 - Manuel Martins ingressa na Ordem Terceira

- 1740 - Estudante Universitário, a expensas da Ordem Terceira de S. Francisco no Colégio de S. Pedro em Coimbra

- 1742 - Lente das Artes no Colégio de S. Pedro.

\footnotetext{
12 - Veja-se Francisco Vaz, Os livros e as Bibliotecas ...

${ }^{13}$ - J. MARCADÉ, Dom Frei Manuel do Cenáculo Vilas Boas. Éveque de Beja, Archevêque d' Evora (1770-1814)..., p. 34.
} 
- 1749 - 5-26 - Doutorou-se em Teologia .

- 1750 - Secretário da Província da Ordem Terceira de S. Francisco de Portugal

- 1757 (Maio) - Cenáculo é escolhido como Cronista da Ordem Terceira

- 25-1-1758 - Nomeado Inspector das igrejas e benefícios das Ordens Militares;

- 1760 - Passa a exercer funções de Censor no Tribunal do Patriarcado de Lisboa

- 1764-12-18 - Nomeado Capela-mor das Armadas Reais

- 1768 - É eleito Provincial da Ordem Terceira

- 1768 -7-4 - Juramento como deputado da Real Mesa Censória

- 1768 -12-7 - Nomeado Confessor do Príncipe da Beira

- 1770- 3-5 - Proposto pelo Rei para Bispo de Beja

- 1770- 3-16 - Presidente da Real Mesa Censória, entre 1770-1777.

- 1771 - Pombal escolheu-o para integrar a Junta de Providência Literária, para reforma da Universidade de Coimbra em 1772.

A proximidade do poder abriu novas possibilidades de encontrar contactos, correspondentes e adquirir novos meios de informação. Numa sociedade como a da segunda metade de setecentos, em que como nos diz Peter Burke persistem as relações clientelares, usufruir de poder engendra toda uma rede de contactos e envolve a prestação de serviços do cliente ao seu patrono. Muitas das cartas enviadas por correspondentes resultam deste tipo de relação clientelar.

Os cargos de D. Frei Manuel, na Real Mesa Censória, possibilitaram as relações com correspondentes muito diversificados, nomeadamente, autores, livreiros, professores régios. A convivência com a Corte e círculo do poder permitiu estabelecer relações com muitos nobres, ministros, e altas individualidades do clero.

Assim como Presidente da Mesa Censória muitos professores régios, seja nos estudos menores ou no Colégio dos Nobres, pedem a intervenção de Frei Manuel para assuntos relativos ao ensino, que vão desde a escolha de manuais ao pagamento de salários ou outros do género; ou pedem o seu patrocínio para publicar as suas obras, dirigem-se-lhe nas épocas festivas, numa nítida tentativa de agradar ao patrono e obter a sua confiança. Precisar em números esta correspondência, ou seja, tentar averiguar as categorias sociais e económicas dos correspondentes, a geografia desta rede e a sua verdadeira dimensão não é tarefa fácil dada a grandeza do fundo. Limitamo-nos aqui a dar o ponto da situação da nossa pesquisa. 
Uma vez que o fundo mais completo é o das cartas enviadas a Frei Manuel, interessanos centrar a nossa análise nestas cartas, para tentar esboçar a rede de correspondentes, a sua dimensão geográfica e tirar ilações sobre a importância dessa rede, sobretudo para o coleccionismo e bibliofilia do prelado. Centramos a nossa pesquisa, relativamente a correspondência catalogada por Alexandre de Gusmão, nas cartas com referências importantes sobre livros e leituras, sobre estudos e manuais adoptados e ainda sobre outras facetas do seu coleccionismo, de peças arqueológicas e obras de arte. Constituímos assim uma base com 1547 cartas com importância para aqueles parâmetros $^{14}$. Tendo como base esta base de dados, reunimos uma amostra significativa que nos permite esboçar a rede de correspondentes de D. Manuel do Cenáculo e que lhe possibilitou uma informação sobre o que se ia passando de importante no pais e no resto do mundo, e como com ela Frei Manuel foi aumentando a sua colecção de livros, antiguidades e obras de arte.

Das 1547 cartas inventariadas 1427 indicam a localidade, mostrando-nos uma rede de nível mundial. No quadro seguinte resumimos as cidades e outras localidades donde provem mais de 12 cartas.

Quadro 2 - Cidades dos Correspondentes

\begin{tabular}{|l|r|r|}
\hline Cidades & Número cartas & $\%$ \\
\hline Lisboa & 590 & 55,14 \\
\hline Roma & 111 & 10,37 \\
\hline Coimbra & 107 & 10,00 \\
\hline Madrid & 104 & 9,72 \\
\hline Sevilha & 33 & 3,08 \\
\hline Faro & 29 & 2,71 \\
\hline Évora & 22 & 2,06 \\
\hline Santarém & 22 & 2,06 \\
\hline Granada & 21 & 1,96 \\
\hline Alcobaça & 19 & 1,78 \\
\hline Veneza & 12 & 1,12 \\
\hline Outras localidades & 357 & 25,02 \\
\hline Totais (Fonte: GUZMÃO, 1944.48 e 1956, VAZ, 2009) & 100 \\
\hline \multicolumn{2}{|c|}{}
\end{tabular}

O domínio de Lisboa é avassalador (55\% do total), mas nota-se uma presença significativa de cartas vindas de capitais estrangeiras; Roma e Madrid, a par de outras cidades de Itália e Espanha ( Sevilha, Granada e Veneza ). A nível nacional Coimbra, Faro e Santarém estão bem representadas. O que podemos concluir é que Frei Manuel

14 - Como dissemos, o catalogo de Gusmão deixou de parte um conjunto assinalável de cartas dirigidas Frei Manuel do Cenáculo, cartas que catalogamos no âmbito do projecto: um total de 1134 cartas. 
tinha correspondentes nos centros vitais para a sua actividade eclesiástica: em Lisboa, naturalmente, porque no país (ontem como hoje) tudo passava pela capital, mas também no centro do mundo católico, a cidade de Roma, e na corte madrilena.

Por pais esta rede mostra-nos uma dimensão geográfica de nível mundial.

Quadro 3 - Países dos correspondentes

\begin{tabular}{|l|r|r|l|}
\hline País & No cartas & $\%$ & Observações \\
\hline Portugal & 1041 & 72,95 & Inclui colónias \\
\hline Espanha & 221 & 15,49 & Canárias) \\
\hline Itália & 135 & 9,46 & \\
\hline França & 9 & 0,63 & \\
\hline Inglaterra & 7 & 0,49 & \\
\hline Holanda & 6 & 0,42 & \\
\hline Bélgica & 3 & 0,21 & \\
\hline USA & 2 & 0,14 & Filadélfia ( 2 cartas) \\
\hline Turquia & 1 & 0,07 & Constantinopla \\
\hline Rússia & 1 & 0,07 & S. Petersburgo \\
\hline Alemanha & 1 & 0,07 & \\
\hline \multicolumn{5}{|c|}{1427} & 100,00 & \\
\hline
\end{tabular}

Nas 1041 cartas de Portugal incluem-se as dos correspondentes de vários territórios ultramarinos: Brasil ( 32), Goa (13), Macau (5), Angola (2), Gondar ( 3), Tanger (2), Moçambique (1), e Cabo Verde (1).

Quem são os correspondentes? Uma análise qualitativa revela-nos uma numerosa plêiade de individualidades do mais diverso estatuto social. Figuram muitos clérigos, desde frades, presbíteros seculares até bispos e arcebispos. Mas também muitos homens de Estado e homens políticos de primeiro plano, como o Marquês de Pombal, o Intendente da Polícia Diogo Inácio de Pina Manique, D. Rodrigo de Sousa Coutinho. Há também muitos professores régios dos Estudos Menores, da Universidade e do Colégio dos Nobres. Figuram também alguns dos nomes mais sonantes do reformismo económico e social, como o Abade Correia da Serra, António Ribeiro dos Santos, José António de Sá, Domingos Vandelli e outros membros da Academia das Ciências. Entre os correspondentes do Bispo de Beja há também um público feminino, mulheres da nobreza, como a Condessa do Vimieiro, algumas que procuravam ajuda em momentos de endividamento das suas casas, como Luísa Margarida Leonor de Weinpoltz, ou outras ainda mais emblemáticas e que usavam a correspondência como meio de obter informações, como a revolucionária de Nápoles, Leonor da Fonseca Pimentel ${ }^{15}$.

\footnotetext{
15 - Veja-se F. VAZ, Instrução e Economia .... p. 241.
} 
Recorrendo de novo aos números, procuramos com base nos dados inventariados, ver quais os correspondentes mais profícuos, os que escreveram mais cartas. Estabelecemos como parâmetro os correspondentes com mais de 15 cartas e o resultado está no quadro que se segue.

Quadro 4 - Correspondentes de Frei Manuel do Cenáculo

\begin{tabular}{|l|r|l|l|}
\hline CORRESPONDENTE & Cartas & Datas & Observações \\
\hline Nicolau Pagliarini & 164 & $1768-1795$ & \\
\hline Fr. Joaquim de Guadalupe & 26 & $1770-1794$ & \\
\hline Fr. Raimundo Pasqual & 24 & $1751-1790$ & \\
\hline Frei Joaquim de Santo Agostinho & 24 & $1792-1802$ & \\
\hline P. José Francisco Correia da Serra & 24 & $1779-1793$ & \\
\hline Fr. Plácido de Andrade Barroco & 23 & $1776-1807$ & \\
\hline João Pedro Ribeiro & 22 & $1797-1804$ & \\
\hline D. Alexandre Gouveia, Bispo de Pequim & 21 & $1775-1792$ & \\
\hline Frei Gregório José Viegas & 21 & $1775-1800$ & \\
\hline Francisco José Maria de Brito & 20 & $1789-1804$ & \\
\hline D. Francisco Gomes Avelar, Bispo do & 18 & $1782-1801$ & \\
Algarve & 16 & $1772-1777$ & \\
\hline DR. Fr. Manuel Nossa Senhora da Estrela & 15 & $1780-1792$ & \\
\hline Dr. Bento José de Sousa Farinha & 15 & $1790-1795$ & \\
\hline Dr. João Vidal da Costa & 15 & $1785-1798$ & \\
\hline D. João Baptista Muñoz & 448 & & \\
\hline TOTAL & & & \\
\hline
\end{tabular}

(Fonte: GUZMÃO, 1944.48 e 1956, VAZ, 2009)

\section{Os Folhetos de Notícias}

Mas além da correspondência e muitas vezes em estreita relação com ela, surgem outros meios de informação e fonte de notícias. Estão neste caso as gazetas e jornais, não apenas as gazetas oficias, como a Gazeta de Lisboa, mas também as gazetas manuscritas, que D. Manuel do Cenáculo solicita aos seus agentes e correspondentes. Centremos a nossa atenção nas gazetas manuscritas. O exemplo mais paradigmático da importância que Frei Manuel atribuía a este meios de informação encontra-se na correspondência que o bispo manteve com Nicolau Pagliarini e Thomas Pagliarini. Trata-se de um fundo documental existente na Biblioteca Pública de Évora e que, além das numerosas cartas, reúne um conjunto assinalável de «folhetos de noticias», para usarmos a terminologia do remetente. Com efeito, Thomas Paglarini, sobrinho de Nicolau Pagliarini, utiliza essa designação, para esta espécie de jornal, pelo menos em 
três cartas, a primeira datada de 20.8.1794 e a segunda de 12.9.1795 e a terceira em $30.12 .1795^{16}$.

Quadro 5 - Cartas e Folhetos de Notícias enviados por Pagliarini

\begin{tabular}{|l|l|l|l|l|l|}
\hline Códice & Folhas & Folhetos & Cartas & Cidades & Anos \\
\hline CXXVIII/1-13 & 387 & & 164 & $\begin{array}{l}\text { Lisboa e } \\
\text { Roma }\end{array}$ & $1768-1795$ \\
\hline CXXVIII/ 1-14 & 305 & 146 & 0 & Roma & $9.4 .1784-3.1 .1786$ \\
\hline CXXVIII /1-15 & 155 & 79 & 0 & Nápoles & $13.5 .1786-20.10 .1787$ \\
\hline CXXVIII/ 1-16 & 317 & 156 & 0 & Roma & $1.1 .1787-31.12 .1789$ \\
\hline CXXVIII /1-17 & 321 & 161 & 6 & Roma & $1.1 .1790-26-12.1792$ \\
\hline CXXVIII /1-18 & 276 & 109 & 34 & Roma & $27.12 .1792-17-6.1795$ \\
\hline CXXVIII /1-19 & 174 & 87 & 38 & Roma & $8.1 .1795-29.6 .1796$ \\
\hline TOTAIS & 1935 & 738 & 242 & & \\
\hline
\end{tabular}

(Fonte: BPE, Cod. CXXVIII/1-13; CXXVIII/ 1-14; CXXVIII /1-15; CXXVIII/ 1-16; CXXVIII /1-17; CXXVIII /1-18; CXXVIII /119)

Os Folhetos de Noticias acompanhavam a correspondência que os Pagliarini mantiveram com Cenáculo. Esta compõem-se de um conjunto assinalável de cartas, muitas reunidas num códice, e que foram catalogadas por Gusmão e outras espalhadas pelos códices dos folhetos.

A correspondência de Nicolau Pagliarini a D. Frei Manuel do Cenáculo, que foi catalogada, reúne um total de 164 cartas, algumas acompanhadas de relações de livros e páginas de gazetas noticiosas ${ }^{17}$. Algumas destas cartas de Pagliarini foram mesmo transcritas na íntegra ${ }^{18}$. Podemos dividir esta correspondência em dois períodos: as primeiras 63 cartas datadas de Lisboa, entre 1768 e 14 de Julho de 1778, época em que Nicolau Pagliarini se encontra em Portugal a exercer as suas funções de Director da Impressão Régia e a organizar as bibliotecas da Ajuda e do Colégio dos Nobres. As restantes cartas, a primeira datada de Milão e as restantes de Roma, entre 1778 e 24 de Fevereiro de 1795, correspondendo ao período em que Pagliarini regressou a Itália e durante o qual foi agente do Bispo de Beja na Cúria Romana. Com efeito, com a morte D. José I em 23 de Fevereiro de 1777 e logo em Maio desse ano, Pagliarini comunica a

\footnotetext{
16 - BPE CXXVIII/1-18 . fls. 252, 258, 268.

17 - BPE COD. CXXVIII/1-13 1768-1795, fls.1r- 397v.

18 - As cartas foram repertoriadas por A. GUZMÃO, Catálogo da Correspondência dirigida a D. Fr. Manuel do Cenáculo vol. 6, Évora, 1956, p. 23-73 e 12 cartas foram transcritas na integra, p.144-183.
} 
sua intenção de voltar a Itália para passar o resto da vida. Decisão que manteve mesmo após ter visto D. Maria I confirmar-lhe a tença de 3.000 cruzados e depois o cargo de Agente de Portugal em Roma, com idêntica a pensão. Conseguida a permissão para o regresso, e também uma ajuda de custo para a viagem de 600.000 réis, Pagliarini regressou a Roma, no Verão de 1778, com escala e paragem em Milão ${ }^{19}$.

O segundo núcleo de cartas, que não foram catalogadas por Gusmão, é composto por um total de 78 cartas, seis de Nicolau Pagliarini e setenta e duas de Thomas Pagliarini, datadas entre 1790 e 1802 e acompanham os folhetos de notícias. Trata-se sobretudo de cartas "romanas", ou escritas da quinta que os Pagliarini tinham próximo de Roma. Estas permitem acompanhar os últimos anos de Nicolau Pagliarini e como aos poucos foi sendo substituído pelo sobrinho, como agente e informador de Cenáculo.

Importa ter presente o contexto cultural e politico em que se integra este fundo documental. Os folhetos de notícias cobrem todo um período recheado de acontecimentos de primeiro plano. Entre 1784-1805 muito se alterou, muitas foram as convulsões politicas e sociais, os acontecimentos que fizeram desabar o Ancien Regime. Bastará aqui falar da Revolução Francesa e das suas repercussões na Europa e no Mundo. Ora estes folhetos permitem acompanhar esta conjuntura política e ver como as elites, particularmente os eclesiásticos, acompanharam este desabar das estruturas existentes.

Com interesse para a história da informação, um dado relevante é o facto de estes folhetos terem uma periodicidade semanal, fazendo lembrar um jornal, ou um semanário noticioso. O correspondente anota dia a dia as notícias que considera relevantes e nalguns casos intitula mesmo o seu jornal: "Notizies de Roma dei 13 al 19 de Agosto" (1784). O próprio formato se mantêm durante todo o período.

O interesse deste fundo, e cingindo-nos aos folhetos de notícias, abarca domínios bem diversos e que vão, desde a Historia Politica - nomeadamente as relações entre os Estados europeus e o Vaticano - até à História da informação - gazetas e imprensa periódica, circulação e difusão das noticias, sem esquecer História do Livro e da Leitura, e a História da Ciência e afirmação da mentalidade científica. Neste último domínio anotamos a referência a sismos e à erupção do Vesúvio e a inundações ou factos semelhantes.

19 - Cf. A. GUZMÃO, Catálogo da Correspondência dirigida... p. . 4273-4277; e BPE COD. CXXVIII/1-13 1768-1795, fls. 101-103. 
Tentemos ver em pormenor dois dos domínios referidos: o da História Política, e particularmente as noticias enviadas sobre a conjuntura revolucionária e o da afirmação da mentalidade científica.

Os folhetos de noticias desmentem o juízo de Alexis de Tocqueville de que os homens de Estado e intelectuais europeus consideraram os primeiros acontecimentos revolucionários mais como uma doença a que periodicamente as monarquias estavam sujeitas, neste caso a Cúria parece ter compreendido que logo no inicio da revolução, os acontecimentos punham em causa as rendas e benefícios que tinha em França e ameaçava a concordata que existia e que tinha sido assinada por Francisco I e Leão X.

De facto, fizemos uma sondagem e constata-se que as convulsões revolucionárias começam a ser noticiadas logo em 1789. As notícias provocam grande consternação na Cúria e preocupação perante os primeiros acontecimentos, particularmente a revolta do povo de Paris e depois o que se passou por toda a França. O relator insiste nos folhetos enviados no espírito de independência que se vai instalando no povo e prognostica mesmo uma grande revolução na Europa. De facto no folheto de 30 de Julho a 5 de Agosto de 1789, diz que através do correio de França chegaram os pormenores sobre a "grande revolução de Paris", que se tinha tomado conhecimento através de uma carta de Génova de 20 de Julho. Afirma que a Cúria está com grande temor por causa das rendas e benefícios que resultavam da concordata de Francisco I com Leão X, temendo que a assembleia não respeite essa concordata. Termina o seu relatório de forma profética: «Se lo spirito de independenza s'introduce nê Populi, vi e multo da temere di una generale Revoluzione» ${ }^{20}$.

Em posteriores folhetos reforça esta ideia de que o espírito de independência e a revolta contra o despotismo, ou como diz, a vontade do povo sacudir o "jugo dos poderosos", se está a propagar às outras nações, incluindo a Itália. Noticia a este propósito que o Rei da Sardenha por altura do casamento do filho pensou em lançar uma imposição sobre os súbditos, mas os súbditos de Novara recusaram pagá-la e o Rei teve de levantar essa $\operatorname{taxa}^{21}$.

A Cúria e todos aqueles que nela viviam não podia deixar de estar preocupada com o evoluir dos acontecimentos, dados os interesses em causa. A este propósito e

\footnotetext{
20 - BPE, cod. CXXVIII 1-16, fls. 273 e 274. Nesta e nas restantes citações dos folhetos mantivemos a ortografia do original

${ }^{21}$ - « ...ovo il Populo há scosso il jiogo dei Potenti, ed a ottenuto la su libertá, va insinuando anche in Itália, e in questo Stato Pontifício un certo spirito de resentimento nella Plebe, per calquer cosa que sucede, per cui que governa procura contentala com moderazione». BPE, cod. CXXVIII/1-16, fl. 279..
} 
continuando esta sondagem, Pagliarini no início de Setembro de 1789 volta a dizer que as noticias de França são "cada vez piores", que elas continuam a afectar o animo do Papa, bem como os cardeais, dizendo que o cardeal Duque de York, sabendo que as duas abadias que tinha em França tinham sido saqueadas pelos populares tinha feito uma reforma geral na economia da sua casa: vendera 12 cavalos e tinha suspendido a esmola que dava em Roma. Tudo porque as rendas que ele tinha em França montava a 35.000 escudos romanos, que estavam agora perdidos ${ }^{22}$.

Mas foi sobretudo a partir da promulgação da Constituição Civil do Clero, em 1791, que o as reacções da Cúria Romana se acentuaram. É isso que se constata com a leitura, que sistematizamos na cronologia que se segue.

\section{Quadro 6 - Notícias em Alguns Folhetos}

\section{Data Folhetos}

5 a 11 de Maio de 1791

21 a 27 de Julho de 1791

30 de Setembro a 5 de Outubro de 1791

19 de Outubro de 1791

27 de Outubro a 2 de Novembro de 1791

1 a 4 de Janeiro de 1792

16 a 22 de Fevereiro de 1792

8 a 14 de Março de 1792

3 a 9 de Julho de 1792

\section{Notícias}

Situação vivida pelo clero em França

Impressão da carta do Marques de Boullé á Assembleia Nacional de França.

Reimpressão da carta do Conde de Provença ao seu irmão, Rei de França.

O Papa ordenou que se estampassem todos os breves, e outros escritos seus, feitos a respeito das "coisas de França".

Os novos bispos de França eleitos de acordo com a constituição, expediram ao Papa uma obra defendendo a sua eleição e o novo sistema de clero decretado pela Assembleia. É referido o título da obra: Acord dês vrais príncipes de l'Evangile, de la Morale, et de la raison avec la constitution Civile du Clergé de France.

Informa que se estamparam publicamente no reino de França escritos horrendos contra a religião e contra a Soberania.

Informa que por ordem do Papa está a trabalhar-se uma resposta ao escrito feito pelos bispos de França com o título "accord".

Diz que Mr. Condorcet, célebre matemático e deputado da Assembleia Nacional, escreveu uma longa carta ao Duque de Alba sobre o estado actual da França, que foi logo estampada e muito aplaudida.

O Papa vendo o andamento das coisas em França na mais obstinada revolução, fez estampar uma colectânea de sermões editados em França, e com o titulo: Preces mamete vespere recitandae ad Divinam opem implorandam in praesentibuo Galliae calamitatibus.

31 de Janeiro 6 de Noticia da execução do rei Luís XVI, em 21-1-1793.

Fevereiro 1793

de 7 a 13 de Fevereiro Reacção do Papa, Pio VI, a morte d Luís XVI. de 1793

22 - BPE, cod. . CXXVIII/1-16, fl. 284. 

Roma relativas aos eclesiásticos franceses.

21 a 27 d Fevereiro de Ataque dos franceses à ilha de Sardenha e a heróica resistência 1793 dos habitantes da ilha aos invasores.

1 a 6 Março de 1793

Carta do Grão-duque a Toscana ao Papa, revelando-lhe a sua neutralidade perante a França.

Noticias sobre a entrada da esquadra inglesa no Mediterrâneo (Fonte: BPE, Cod. CXXVIII /1-15; CXXVIII/ 1-16; CXXVIII /1-17; CXXVIII /1-18; CXXVIII /1-19)

O simples enunciado das notícias demonstra o que já referimos, a Cúria Romana e o clero começaram a encarar a partir de 1791 a revolução como algo que tinha de ser combatido, ou seja, passam definitivamente para a contra-revolução. Sem dúvida que os ataques aos interesses eclesiásticos, a nova forma de eleição dos bispos franceses e "os escritos horrendos contra a religião", contribuíam de forma decisiva para deixar o Vaticano em sintonia com os contra-revolucionários.

Um outro dado que o elenco permite constatar é a importância que um e outro campo revolucionários ou defensores da cúria romana - atribuem as publicações seja aos livros que se vão escrevendo sobre tema, seja aos jornais e panfletos. Como se constata, o Papa reuniu tudo o que publicou alusivo a revolução num só livro, os bispos franceses eleitos de acordo coma constituição fazem um livro para fundamentar o novo sistema, que por sua vez origina uma publicação papal contra. Neste campo, continua-se a tradição já arreigada do século das luzes, em que o confronto razão fé originou toda uma literatura apologética ou contra a religião. Agora, contudo, os livros e a imprensa periódica são armas de arremesso político a que se atribui cada vez mais força.

Mas o facto que verdadeiramente mudou a opinião das elites eclesiásticas sobre os acontecimentos e França foi a execução do rei Luís XVI, em 21-1-1793. Os folhetos de notícias são um bom exemplo do alarme e angústia que o facto provocou na Cúria Romana. A noticia é dada no fim do folheto d 31 de Janeiro a 6 de Fevereiro, o que pressupõe que chegou a Roma por volta de 5 de Fevereiro: «... com o correio de Milão receberam-se as cartas de França que trouxeram a infausta novidade da morte do rei, que pôs em consternação toda esta corte». No folheto seguinte, de 7 a 13 d Fevereiro de 1793, Thomas Pagliarini desenvolve melhor a infausta notícia:

No dia 5 com o correio de Florença chegaram as cartas de França com a infaustíssima nova da morte do Rei ocorrida no dia 21 de Janeiro. O cardeal Zelada esperou, que o Santo Padre terminasse o repouso, que costuma tomar depois do almoço, para lhe comunicar o Despacho. Pio VI ficou tão aflito e surpreso, que começou a suar abundantemente e continuou na sua angústia por 
muitas horas. Toda a cidade demonstrou uma dor extrema, e a Madame de França com o Cardeal Bernir imediatamente se vestiram de luto com toda a família ${ }^{23}$.

Este folheto é acompanhado de uma carta do redactor, em que lhe envia um soneto alusivo a morte do Rei de França.

No folheto seguinte, datado de 14 a 20 de Fevereiro o tema continua a ocupar um lugar central nas notícias enviadas. Pagliarini informa agora as disposições tomadas pela Secretaria de Estado de Roma, que temendo que alguns padres e frades, fossem do partido jacobino, mandou uma circular a todos os bispos para obrigar todos os eclesiásticos a fazerem o juramento, segundo os formulários determinados por Pio IV e Alexandre VII (feitos para combater doutrinas erróneas como deísmo e jansenismo). O governo papal encarregou também os bispos de enviar para a Secretaria de Estado todas as informações e documentos de cada um dos padres franceses que habitassem na diocese. Por outro lado, o governo considerando as grandes desordens e distúrbios que sucediam diariamente com os insultos do povo contra todos os que eram acusados de serem franceses, publicou um édito decretando pesadas penas a quem insultasse o maltratasse qualquer pessoa por ser francesa. Ainda neste folheto, informa sobre as esperanças que o Papa deposita na protecção dos ingleses, particularmente no Príncipe Augusto, contra a ameaça francesa que pende sobre toda a Itália.

No folheto de 21 a 27 de Fevereiro de 1793, noticia o ataque dos franceses à ilha de Sardenha e a heróica resistência dos habitantes da ilha aos invasores. Diz ainda que se aguarda com impaciência as noticias sobre a entrada da esquadra inglesa no mediterrâneo, sobre a qual se coloca a esperança de que a Itália não seja invadida pelos Franceses.

No folheto de 1 a 6 Março de 1793. Informa que o Grão-duque a Toscana enviou uma carta ao papa, revelando-lhe a sua neutralidade perante a França. Noticia também que através do correio de Lisboa de 2 de Janeiro, chegaram noticia sobre a entrada da esquadra inglesa no Mediterrâneo.

Relativamente a obras periódicas impressas, é possível comprovar que o bispo de Beja era um bom leitor de Gazetas e Jornais, demonstrando um interesse em estar bem informado sobre os factos contemporâneos e que o discurso oficial deixava circular ou publicar. Tal como refere Robert Darton, as gazetas e jornais, porque estavam sujeitas à censura, veiculavam só os factos que não beliscavam o poder, mas em domínios como

\footnotetext{
${ }^{23}$ - BPE, cod. . CXXVIII/1-16, fl. 293. Tradução do italiano feita por nós.
} 
os da ciência e técnica não deixam também de ser importantes meios de difusão das inovações, das descobertas e novos métodos que se iam afirmando. Temos no caso nacional bons exemplos como os do Jornal Enciclopédico ou mesmo o da Gazeta de Lisboa.

O quadro que se segue inventaria as publicações periódicas adquiridas por Frei Manuel do Cenáculo, entre 1768-1794, através de Nicolau Pagliarini.

\section{Quadro 7 - Publicações Periódicas}

\begin{tabular}{||l|r|r|l||}
\hline TíTULO & TOMOS & PREÇO & ANOS \\
\hline Annali Eclesiiastici di Firenze & 7 & 10.600 & $1780-1789$ \\
\hline Efemeridi Letterarie di Roma & 13 & 19.200 & $1778-1790$ \\
\hline Ephemerides Helmstadiensis & 6 & 9.680 & $1771-1776$ \\
\hline Gazeta Firenze & 4 & 13.600 & $1777-1791$ \\
\hline Gazeta Lugano & 10 & 36.120 & $1770-1779$ \\
\hline Gazeta Notizie del Mondo & 2 & 5.600 & $1785-1786$ \\
\hline Gazeta Universale di Firenze & 3 & 8.400 & $1787-1789$ \\
\hline Journal Litteraire de Berlin & 23 & 13.560 & $1775-1776$ \\
\hline Giornale Ecclesiastico di Roma & 7 & 13.800 & $1786-1791$ \\
\hline Giornale de Letterati d' Italia & 45 & 20.000 & - \\
\hline Giornale de Letterati di Roma & 7 & 6.300 & 1759 \\
\hline Ephemerides Bononiens & 2 & 2.800 & 1775,1786 \\
\hline TOTAIS & 128 & 159.660 & \\
\hline
\end{tabular}

Constata-se, portanto, que o bispo estava bem fornecido de publicações periódicas, que iam lentamente adquirindo o meio para afirmação da opinião pública, numa época marcada por eventos tão determinantes como a Revolução Francesa e a Independência dos Estados Unidos. Era natural que as gazetas entre 1776-1792 se debruçassem com pormenor sobre os acontecimentos revolucionários e, portanto, o prelado, apesar de se encontrar no Alentejo profundo, pode com toda a certeza ficar bem informado sobre estes eventos e as suas consequências.

\section{Considerações Finais}

Em Beja Frei Manuel lançou mão dos meios de informação do seu tempo para olhar para o mundo e acompanhar as convulsões políticas e sociais que sobre ele se iam abatendo. As noticias chegavam pelas cartas, pelos muitos visitantes que demandavam o 
paço de Beja, pelos jornais e gazetas, proporcionando-lhe uma boa leitura dos acontecimentos e até um bom prognóstico para o futuro, como demonstra em carta enviada ao amigo Plácido Barroco.

Aqui me acho lendo o mundo e ouvindo o que chegou de Lisboa há 24 horas. É tudo para sentir seja daqui seja de acolá. Vai do século, mas este começa agora. Os Planos de Luís $14 .^{\circ}$ renderam todo o século que acabou há pouco: agora a cena começa e requinta, e ainda se buscam os eixos: esta lida levará anos: depois entrará a bulha sobre o movimento da máquina nova. O mais é que não há cabeças para a coisa, e este é o maior mal: estão desavindos, e desentendidos, e em Nós há-de quebrar escudo e lança externos ${ }^{24}$.

${ }^{24}$ - CENÁCULO, Carta a Frei Plácido Barroco, 8 de Junho de 1794, cit. Francisco VAZ, Os Livros e as Bibliotecas ..., p. 336. Sublinhado nosso. 


\section{BIBLIOGRAFIA}

\section{1 - MANUSCRITOS}

Biblioteca Pública Évora (BPE), COD. CXXVIII/1-13 [Cartas de Nicolau Pagliarini a

D. Frei Manuel do Cenáculo], Lisboa, Milão e Roma, 1768-1795, fls. 397

Biblioteca Pública Évora (BPE), Cod CXXVIII/2-9, [Cartas de Frei Manuel do

Cenáculo a diversos],np.

Biblioteca Pública Évora (BPE), Cod. CXXVIII/2-11, [Rascunhos autógrafos de Frei Manuel do Cenáculo], Beja e Évora, 1777- 1814, fls 173.

Biblioteca Pública Évora (BPE), Cod. CXXIX/1-19 [Diário de D. Frei Manuel do Cenáculo], Beja 1784- 1788, fls. 224

Biblioteca Pública Évora (BPE), Cod. CXXIX/1-20, 19 [Diário de D. Frei Manuel do Cenáculo] Beja, 1788-1794, fls. 218 .

Biblioteca Pública Évora (BPE), Cod. CXXIX/1-21, [Diário de D. Frei Manuel do Cenáculo], Beja e Évora (1803), 1794-1812, fls. 290.

\section{2 - IMPRESSOS}

ALCOCHETE, Nuno Daupias , Humanismo e Diplomacia. Correspondência Literária (1789-1804) de Francisco José Maria de Brito com D. Frei Manuel do Cenáculo, Paris, Fundação Calouste Gulbenkian- Centro Cultural Português, 1976.

BARBIER, Frederic, Histoire du livre, Paris, Armand Collin, 2001.

BARJAS, Eduardo Salas, « Cartas de Académicos de la Historia al Obispo de Beja, Frei Manuel do Cenáculo», Boletim de La Real academia de La Historia, Madrid, t. CXCI, 1994, pp. 517-561.

BREWER, John, «Reading and Readers in 18th century Britain», Cultura. História e Teoria das Ideias, vol IX, 1997, p.159-185.

CAEIRO, Francisco da Gama, Dispersos, Lisboa, Estudos Gerais série Universitária, 1998. 
CASTRO, Zília Osório de, «Jansenismo versus Jesuitismo. Niccoló Pagliarini e o projecto político pombalino», Revista Portuguesa de Filosofia, 52(1996), págs. 223232.

CENÁCUlO, Manuel do, Cuidados Literários, Lisboa: Officina de Simão Thadeo Ferreira, 1791.

CENÁCUlO, Manuel do, Instrução Pastoral sobre os Estudos Fysicos do Clero, Lisboa: Regia Officina Typografica, 1786.

CHARTIER, Roger, «Des "secrétaires" pour le peuple ? Les modèles épistolaires de l'Ancien Régime entre littérature de cour et livre de colportage», in CHARTIER, Roger, dir de La Correspondance. Les usages de la lettre au XIXe. Siècle, Paris 1991.

CHARTIER, Roger, «Livres, Lecteurs, lectures», Le Monde des Lumières, Paris: Aubier, 1999, págs. 284-315.

Coleccionismo y bibliotecas: (siglos XV-XVIII), dir. María Luisa López-Vidriero, Pedro M. Cátedra, ed. Mª Isabel Hernández González, Salamanca, Universidad, 1998. CURTO, Diogo Ramada et alli, As gentes do Livro. Lisboa, século XVIII, Lisboa, Biblioteca Nacional, 2007

DARNTON, Robert, An Early Information Society, 2000, Consultado em 24-9-2008, diponivel em http://www.indiana.edu/ ahr/darnton/texts/p03.html

DIAS, Luís de Carvalho, Inéditos de António Ribeiro dos Santos, Coimbra, 1976 ( sep. Boletim da Biblioteca da Universidade de Coimbra, Vol. XXXVIII.

ESPANCA, Túlio, «Diário da viagem do Bispo de Beja D. Manuel do Cenáculo a Vila Viçosa em 1785», Revista a cidade de Évora, 63-64 (1981-1982), págs. 163-193.

ESPANCA, Túlio, «Subsídios para a História da Biblioteca Pública de Évora», Revista a cidade de Évora, 63-64 (1981-1982), págs. 193-267.

FARIA, Manuel Severim de Faria (1655), Notícias de Portugal. Introdução e notas de Francisco Vaz, Lisboa, Colibri, 2003.

GUZMÃO, Armando Nobre de e ALVES, António Leandro Sequeira, Catálogo da Correspondência dirigida a D. Fr. Manuel do Cenáculo vol. 6, Évora, 1956.

GUZMÃO, Armando Nobre de, Catálogo da Correspondência dirigida a D. Fr.

Manuel do Cenáculo, Évora, 1944-1948, 5 vols.

MARCADÉ, Jacques, Dom Frei Manuel do Cenáculo Vilas Boas. Éveque de Beja, Archevêque d' Evora (1770-1814), Paris, Centro Cultural Português - Fundação 
Clouste Gulbenkian, 1978.

MAXWELL, Kenneth, Pombal paradox of the enlightenment, Cambridge, Univerity Press, 1995.

McMURTRIE, Douglas, O Livro. Impressão e Fabrico, Lisboa, Fundação Gulbenjian, 1997.

MORATO, Francisco Trigoso de Aragão, «Elogio Histórico de D. Frei Manuel do

Cenáculo», História e Memória da Academia Real das Ciências, Lisboa, Typografia da Academia, 1815, pp. 63-120.

PEREIRA, José Esteves Pereira, O pensamento político em Portugal no Século XVIII, Lisboa: Imprensa Nacional, 1989.

PEREIRA, José Esteves, «O pensamento filosófico em Portugal- Conhecimento, Razão e Valores no séc. XVIII e XIX» in Cultura História e Filosofia, vol. V, Lisboa, 1986, pp. 751-781.

RIBEIRO, José Silvestre, Historia dos estabilicimentos scientificos litterarios e artisticos de Portugal nos successivos reinados da monarchia, Lisboa: Academia Real das Sciências, 1871-1914; 19 v : Apontamentos históricos sobre bibliotecas portuguesas, 1914.

SALGADO, Vicente, Memorias Ecclesiasticas do Reino do Algarve, Lisboa, Régia Oficina Typografica, 1786.

SOUZA, Evergton Sales de, Jansénisme et Reforme de l'Eglise dans L'Empire Portugais. 1640 à 1790, Paris: Fundação Calouste Gulbenkian- Centre Culturel Calouste Gulbenkian, 2004.

VAZ, Francisco, «Piedade Cristã e reformismo económico na acção pastoral de Frei Manuel do Cenáculo», Actas do Colóquio Internacional Piedade Popular Sociabilidades Representações Espiritualidades, Lisboa, Terramar - Centro de História da Cultura, 1999, pp. 371- 392.

VAZ, Francisco, «As Bibliotecas e os Livros na obra de D. Frei Manuel do Cenáculo», La Memoria de Los Libros. Estudios sobre la historia del escrito y de la lectura en Europa y América, Salamanca: Instituto de História del Libro y de La Lectura, 2003, pp. 483-498.

VAZ, Francisco, «Ciência e Técnica na obra de D. Frei Manuel do Cenáculo (17241814), Actas do $1^{\circ}$ Congresso Luso-Brasileiro de História da Ciência e Técnica, Évora: 
Universidade de Évora, 2001, págs. 262-274.

VAZ, Francisco, «O catecismo no discurso da ilustração portuguesa do século XVIII», Cultura. Revista de História e Teoria das Ideias, Vol. X, Lisboa, 1998, pp. 217-240.

VAZ, Francisco, Instrução e Economia. As ideias económicas no discurso da Ilustração Portuguesa, Lisboa, Colibri, 2002.

VAZ, Francisco e CALIXTO, José António, coord. de, D. Frei Manuel do Cenáculo Construtor de Bibliotecas, Vale de Cambra, Caleidoscópio, 2006.

VAZ, Francisco, «A ideia de Biblioteca Pública em Portugal nos séculos XVIII e XIX», Revista do Centro de Estudos de Além-mar, n. , 2006, pp.169-184

VAZ, Francisco, «D. Frei Manuel do Cenáculo e o Ensino no Colégio do Espírito Santo», REVUÉ. Revista da Universidade de Évora, no 10-11, Abril de 2009, pp. 146159.

VAZ, Francisco, O Saque de Évora pelos Franceses em 1808. Textos Históricos, Vale de Cambra, Caleidoscópio, 2008.

VAZ, Francisco, coord. Os Livros e as Bibliotecas no Espólio de D. Frei Manuel Do Cenáculo, Lisboa, Biblioteca Nacional de Portugal, 2009.

VAZ, Francisco, coord, D. Manuel do Cenáculo: Instruções Pastorais, Projectos de Bibliotecas e Diário, Porto, Porto Editora, 2009. 